(1)

CrossMark

\title{
Caution in interpretation of abnormal carbon monoxide diffusion capacity in COVID-19 patients
}

\begin{abstract}
To the Editor:
We read with much interest the recent findings published in the European Respiratory Journal of reduced gas transfer in patients following coronavirus disease 2019 (COVID-19). Mo et al. [1] investigated conventional pulmonary function in survivors of mild, moderate and severe COVID-19 approximately 20-30 days after onset of symptoms. While patients had relatively normal spirometry, diffusing capacity of the lung for carbon monoxide $\left(D_{\mathrm{LCO}}\right)$ was reduced in $50 \%$ and $D_{\mathrm{LCO}} /$ alveolar volume $\left(V_{\mathrm{A}}\right)$ (or $K_{\mathrm{CO}}$, to avoid misinterpretation) reduced in $25 \%$. These findings are welcome as they provide significant insight into the long-term lung function impairment associated with COVID-19.
\end{abstract}

In response, NUSAIR [2] contributed the interpretation that "low $D_{\text {LCO }}$ is caused mainly by reduced alveolar volume, and not residual interstitial abnormalities or pulmonary vascular abnormalities caused by COVID-19", i.e. normal capillary-alveolar units. However, we believe that this interpretation does not consider the complex relationship between $V_{\mathrm{A}}, D_{\mathrm{LCO}}$ and $K_{\mathrm{CO}}$, and may prematurely rule out the presence of abnormal gas exchange. To demonstrate our point, figure 1 illustrates the expected effect of a reduction in $V_{\mathrm{A}}$ on $D_{\mathrm{LCO}}$ and $K_{\mathrm{CO}}$ due to either suboptimal alveolar expansion or loss of alveolar units (with normal expansion in communicating alveoli) [3]. Firstly, it is evident that in the "severe pneumonia" patients in the study by Mo et al. [1], the impairment in $D_{\text {LCO }}$ [1] (represented by the star) is considerably greater than expected if a reduction in $V_{\mathrm{A}}$ was the sole abnormality, regardless of the mechanism for the reduced $V_{\mathrm{A}}$. Secondly, a reduction in $V_{\mathrm{A}}$ due to either aforementioned mechanism would be is associated with an increase in $K_{\mathrm{CO}}$, which is opposite to the reduced $K_{\mathrm{CO}}$ in many of the discharged patients with severe COVID-19 [3]. This reduction in $K_{\mathrm{CO}}$ suggests that loss of alveolar units is not sufficient to cause the observed impairment in $D_{\text {LCO }}$

Thus, while the $D_{\mathrm{LCO}}$ findings of Mo et al. [1] are partially explained by reduced $V_{\mathrm{A}}$, the reduction in $K_{\mathrm{CO}}$ measured at that reduced $V_{\mathrm{A}}$ also implicates abnormal gas exchange. Whether this is due to disruption of
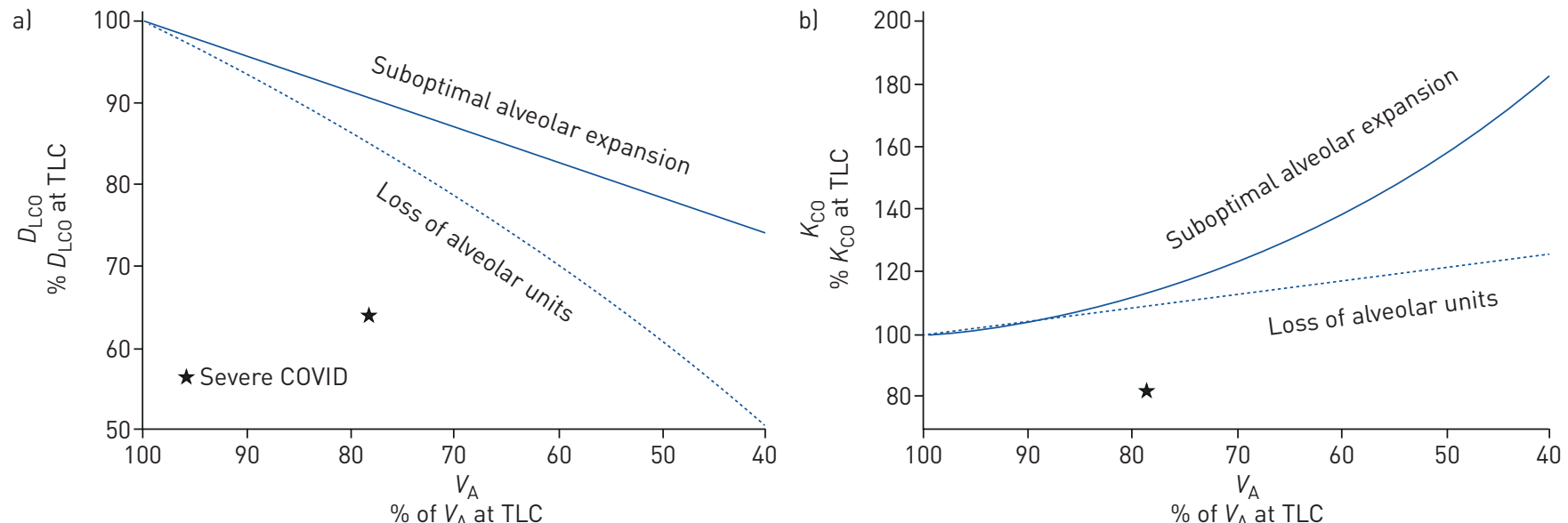

FIGURE 1 The relationship between alveolar volume $\left(V_{\mathrm{A}}\right)$ and, a) diffusing capacity of the lung for carbon monoxide $\left(D_{\mathrm{LCO}}\right)$ and b) rate constant for carbon monoxide uptake $\left(K_{\mathrm{CO}}\right)$, are plotted as a percentage of the value at total lung capacity (TLC). The relationships are shown for two situations that result in reduced $V_{\mathrm{A}}$ : suboptimal alveolar expansion ( $D_{\mathrm{LCO}}$ and $K_{\mathrm{co}}$ measured at volumes below maximum TLC, solid line); and loss of alveolar units (e.g. theoretical removal of lobules or lobes with remaining lung expanded to its normal TLC, dashed line). The star represents the group mean data of the "severe pneumonia" from Mo et al. [1]. Mean $V_{\mathrm{A}}$ was calculated as mean percent predicted $D_{\text {Lco/mean }}$ percent predicted $K_{\mathrm{CO}}$. The relationship between $V_{\mathrm{A}}, D_{\mathrm{LCO}}$ and $K_{\mathrm{CO}}$ was calculated using the equations as described in [3]; for suboptimal alveolar expansion, $K_{\mathrm{CO}}=0.43+$ $\left(0.57 / V_{A}\right)$; for loss of alveolar lung units, change in $K_{\mathrm{CO}}=0.4 x+2.1$, where $x$ is the proportion of volume diverted to the remaining lung; for both scenarios, $D_{\mathrm{LCO}}=V_{\mathrm{A}} \times K_{\mathrm{CO}}$. 
the alveolar-capillary barrier or abnormal pulmonary blood volume cannot be determined based on their data. Lung fibrosis associated with acute respiratory distress syndrome in COVID-19 patients [4] would likely damage alveolar-capillary units, leading to loss of alveolar units and impaired gas exchange. The result would be a reduction in both $V_{\mathrm{A}}$ and $K_{\mathrm{CO}}$ (for the reduced $V_{\mathrm{A}}$ ). There is increasing suggestion of altered pulmonary haemodynamics in COVID-19 patients [5], including vascular pruning and reduced pulmonary blood volume measured via high resolution computed tomography [6]. Use of more specific measures of the alveolar-capillary membrane, such as combined $D_{\text {LCO }}$ and diffusing capacity of the lung for nitric oxide measurements or advanced imaging techniques, are likely required to determine whether interstitial abnormalities or pulmonary vascular abnormalities contribute to reduced $D_{\text {LCO }}$ in patients who have recovered from COVID-19.

@ERSpublications

Reduced $K_{\mathrm{CO}}$ in discharged patients with COVID-19 suggests persistent abnormalities in gas exchange. Further research is required to understand why. https://bit.ly/2Hb00gq

Cite this article as: Chapman DG, Badal T, King GG, et al. Caution in interpretation of abnormal carbon monoxide diffusion capacity in COVID-19 patients. Eur Respir J 2021; 57: 2003263 [https://doi.org/ 10.1183/13993003.03263-2020].

David G. Chapman $\oplus^{1,2}$, Tanya Badal ${ }^{1,3}$, Gregory G. King ${ }^{1,4,5,6}$ and Cindy Thamrin $\overbrace{}^{1,6}$

${ }^{1}$ Airway Physiology and Imaging Group and Woolcock Emphysema Centre, The Woolcock Institute of Medical Research, The University of Sydney, Glebe, Australia. ${ }^{2}$ School of Life Sciences, Faculty of Science, University of Technology Sydney, Ultimo, Australia. ${ }^{3}$ Dept of Thoracic Medicine, Concord Repatriation General Hospital, Concord, Australia. ${ }^{4}$ Dept of Respiratory Medicine, Royal North Shore Hospital, St. Leonards, Australia. ${ }^{5}$ NHMRC Centre of Excellence in Severe Asthma, New Lambton Heights, Australia. ${ }^{6}$ Faculty of Medicine and Health Sciences, The University of Sydney, Sydney, Australia.

Correspondence: David G. Chapman, University of Technology Sydney, School of Life Sciences, 431 Glebe Point Road, Glebe, New South Wales 2037, Australia. E-mail: d.chapman@sydney.edu.au

Received: 25 Aug 2020 | Accepted: 14 Oct 2020

Conflict of interest: D.G. Chapman has nothing to disclose. T. Badal has nothing to disclose. G.G. King reports personal fees, non-financial support and other from AstraZeneca, Boehringer Ingelheim, GSK, Menarini, MundiPharma and Novartis (consultancy fees for talks, chairmanship, advisory boards and conference sponsorship), unrestricted research grants from NHMRC, Boehringer Ingelheim, CycloPharma, GlaxoSmithKline, Menarini, MundiPharma, philanthropic individuals and societies, and non-financial support from Restech (research collaboration and in-kind support), outside the submitted work. C. Thamrin has nothing to disclose.

\section{References}

1 Mo X, Jian W, Su Z, et al. Abnormal pulmonary function in COVID-19 patients at time of hospital discharge. Eur Respir J 2020; 55: 2001217.

2 Nusair S. Abnormal carbon monoxide diffusion capacity in COVID-19 patients at time of hospital discharge. Eur Respir J 2020; 56: 2001832.

3 Hughes JM, Pride NB. Examination of the carbon monoxide diffusing capacity (DLCO) in relation to its KCO and VA components. Am J Respir Crit Care Med 2012; 186: 132-139.

4 Spagnolo P, Balestro E, Aliberti S, et al. Pulmonary fibrosis secondary to COVID-19: a call to arms? Lancet Respir Med 2020; 8: 750-752.

5 Potus F, Mai V, Lebret M, et al. Novel insights on the pulmonary vascular consequences of COVID-19. Am J Physiol Lung Cell Mol Physiol 2020; 319: L277-L288.

6 Lins M, Vandevenne J, Thillai M, et al. Assessment of small pulmonary blood vessels in COVID-19 patients using HRCT. Acad Radiol 2020; 27: 1449-1455. 